\title{
O CONFLITO ENTRE ISRAEL E PALESTINA EM 2014:
}

A SOLIDARIEDADE BASTA?

Luciana Saab ${ }^{1}$

O ano de 2014 foi declarado oficialmente pela Organização das Nações Unidas o Ano Internacional de Solidariedade com o Povo Palestino. Há um ano, a assinatura dos primeiros acordos de paz entre israelenses e palestinos completou duas décadas, e o consenso entre analistas, acadêmicos e as populações de ambos lados é, de que, o processo de paz nos moldes de conversações bilaterais conduzidas pelos Estados Unidos fracassou em atingir um fim para o conflito ou ao menos promover uma melhoria no relacionamento entre as partes a longo prazo. Um novo confronto ocorrido na Faixa de Gaza neste ano mostra que o embate entre Israel e palestinos não está próximo de acabar, e que as perspectivas para o futuro podem ser ainda mais negativas. Tendo em vista a homenagem das Nações Unidas ao povo palestino com a escolha do tema oficial do ano e os horrores sofridos por ele nesse mesmo período, cabem algumas considerações acerca da situação atual do conflito Israel-Palestina e sobre a atuação da ONU durante esse processo.

Mediadas pelo secretário de Estado americano John Kerry, as últimas tentativas de se estabelecer um acordo de paz entre o governo israelense de Benjamin Netanyahu e a Autoridade Nacional Palestina de Mahmoud Abbas chegaram a um impasse semelhante ao visto em situações anteriores. Para os palestinos, é impensável negociar a paz com israelenses enquanto a expansão na construção de assentamentos sobre a Cisjordânia não for interrompida, e enquanto o direito de retorno das famílias de refugiados palestinos expulsos de sua terra com a guerra de criação de Israel em 1948 não for admitido por Israel. Já para o Estado sionista, não é possível atingir a paz através

1 Graduada em História pela Universidade de São Paulo e mestranda em Relações Internacionais pelo Programa de Pós-Graduação San Tiago Dantas (UNESP-UNICAMP-PUCSP) 
de negociações enquanto a ANP não puder garantir a coibição da violência por parte de grupos palestinos que não o reconheçam como legítimo e soberano.

Recentemente, o primeiro-ministro israelense adicionou uma exigência: a Palestina deve reconhecer Israel como um Estado judaico. A vontade israelense representa uma novidade e um novo obstáculo para o avanço das conversas de paz. É uma novidade, pois, a Organização pela Libertação da Palestina já reconheceu oficialmente a existência do Estado israelense na assinatura dos Acordos de Oslo em 1993, momento de criação da ANP. Além disso, a cartilha da organização sofreu alterações para que explicitasse tal reconhecimento. A demanda consiste ainda em um obstáculo, pois, ao exigir que se aceite o caráter judaico de Israel, Netanyahu pede que a liderança palestina abra mão de seu histórico na região e desista do direito de retorno dos refugiados, deixando os cerca de cinco milhões de palestinos deslocados em situação permanente de marginalidade.

Diante da estagnação das negociações de paz, a ANP parece se voltar às Nações Unidas como entidade que possa tomar medidas efetivas para terminar a ocupação militar israelense e com isso o conflito. Sob protestos de americanos e israelenses, em 2011 Abbas solicitou a adesão da Palestina como Estado-membro na organização, porém esse pedido foi prontamente negado pelos EUA, que possuem poder de veto no Conselho de Segurança. Uma vitória palestina, embora menor, veio em 2012, quando a Assembleia Geral aprovou a elevação do status da OLP para Estado não-membro. Na prática, como a grande maioria das medidas da ONU, a adesão da Palestina foi um marco simbólico, pois se admitiu a referência aos palestinos e a seus representantes como pertencentes a um Estado próprio. Porém, na prática, a delegação palestina continua possuindo direitos reduzidos, em situação comparável apenas à do Vaticano. Com isso, afinal, é possível perguntar: qual o papel da ONU no conflito, e até onde se estende sua influência?

A organização teve papel fundamental ao propor o Plano de Partilha da região em 1947, após a retirada dos britânicos do mandato lá estabelecido pela extinta Liga das Nações. Porém, desde a aceitação do plano pelas lideranças sionistas, a recusa dos Estados árabes e de palestinos em aceitá-lo, e as consequentes guerras que seguiram, a organização foi capaz apenas de elaborar inúmeras resoluções que pedem pelo término dos confrontos, assim como exigem a retirada das forças israelenses de Gaza e Cisjordânia, deliberação contestada por Israel no momento da guerra de 1967, quando 
foram ocupadas também as Colinas de Golã. Isso não significa que a contestação de Israel sobre a resolução 242 fosse de fato necessária: que punição há para aqueles que a descumprem?

O fato é que a Organização das Nações Unidas não possui autonomia para tomar decisões políticas e implantá-las, seja através do planejamento de intervenções humanitárias, ou através de meios pacíficos. A ONU pode consultar seus membros, emitir resoluções favoráveis ou desfavoráveis em relação às reivindicações nacionais palestinas e cobrar um esforço internacional para que a paz seja atingida, porém, nada de concreto pode ser feito sem unanimidade no Conselho de Segurança, um verdadeiro beco sem saída para a OLP. Isso ocorre devido à presença no Conselho dos Estados Unidos, declarados aliados incondicionais de Israel. Um bom exemplo da atuação dos americanos nas Nações Unidas foi o recente caso da votação pela investigação da prática de crimes de guerra por Israel na Faixa de Gaza, em que os Estados Unidos foram os únicos a se posicionarem contra.

Diante da impossibilidade dos órgãos da ONU em tomar ações efetivas que ultrapassem o discurso diplomático, limitados por sua própria estrutura, sobrou a eles cumprir um papel meramente paliativo, embora essencial. A Agência das Nações Unidas de Assistência aos Refugiados da Palestina (UNRWA, em inglês) foi criada para lidar exclusivamente com a questão da população refugiada palestina devido ao número de pessoas que se enquadrava nessa situação, até então inédito como consequência de conflitos regionais. Há cerca de sessenta anos a UNRWA oferece assistência humanitária, serviços sociais, de saúde e de educação para a população refugiada, inclusive ajuda de emergência em casos de conflitos armados. A agência não possui função nas negociações de paz, atuando somente como assistente humanitária, de acordo com seguidos mandatos aprovados e renovados pela Assembleia Geral. Por outro lado, sua operação se estende não apenas aos territórios administrados pela ANP, mas também na Jordânia, Líbano e Síria.

Por isso, de modo geral, ao passo em que não se mostrou eficiente em articular as partes de forma a se atingir um acordo em nome da paz baseado no respeito às reivindicações nacionais de cada lado e em concessões necessárias, ou em punir devidamente o descumprimento com a lei internacional e os direitos humanos detalhados em sua própria cartilha, a ONU realiza um trabalho fundamental para a manutenção da condição de vida digna dos refugiados palestinos. Essa frente de atuação, 
por sua vez, encontra seus próprios desafios. 0 alto número de refugiados e seus descendentes em diferentes países exige que seja destinado à agência verbas que por vezes não se mostram suficientes, sobretudo com a necessidade de auxílio também aos refugiados sírios, deslocados aos milhões com o corrente conflito civil. Além disso, as unidades administradas pela UNRWA, como escolas e centros médicos, deixaram de ser um refúgio seguro para a população civil palestina, visto que nas últimas operações militares israelenses sobre Gaza, hoje afogada em grave crise humanitária, nem ao menos essas instituições foram poupadas dos bombardeios estratégicos.

O conflito ocorrido em Gaza neste ano mostra, por si só, duas tendências qualitativamente opostas. Do ponto de vista local, o que se viu com o episódio da Operação Margem Protetora foi o fortalecimento de um discurso ultranacionalista israelense, que levantou o prestígio político da extrema-direita, atualmente no poder, levando à manifestações racistas e discriminatórias dentro de Israel. 0 perigo da ascensão da extrema-direita israelense está, também, no fato de que a grande maioria de seus representantes hoje sequer admite a possibilidade de criação do Estado palestino.

O recém-empossado presidente israelense, Reuven Rivlin, pertence ao partido governista Likud e defende a expansão de assentamentos sobre a Cisjordânia como forma de se estabelecer a "Grande Israel", projeto que passa por cima de qualquer limitação territorial da Palestina e alcança o vale do Rio Jordão, na fronteira com a Jordânia. Do lado palestino, o partido Hamas, cujo braço armado promove centenas de ataques aéreos sobre Israel - considerado terrorista não apenas por israelenses, mas pelos Estados Unidos e União Europeia - ganha moral ao resistir a repetidas tentativas de um dos exércitos mais bem equipados do mundo em dar fim a suas operações. Diante da passividade e desmoralização do governo de Mahmoud Abbas na Autoridade Nacional Palestina dado o fracasso das conversas de paz, o Hamas se fortalece e desponta para alguns palestinos como a única fonte de resistência contra a política de ocupação israelense.

Dessa forma, ambos os lados mostram uma radicalização política e ideológica que os afasta do caminho adotado até poucos anos atrás e que, de forma contrária, parece levar a um grande retrocesso no que diz respeito à aceitação mútua entre israelenses e palestinos. É preciso lembrar que as lideranças no poder hoje não foram as responsáveis pela assinatura de Oslo e atentar para possíveis desvios de curso das negociações pacíficas em nome de um extremismo que tende a pedir pela destruição total do inimigo. 
A perspectiva mais positiva sobre o conflito é a de que, neste ano, houve como em nenhum outro caso de confronto uma grande mobilização internacional, sobretudo através das redes sociais e manifestações pacíficas nas ruas de grandes centros urbanos mundo afora em nome da resolução do conflito e em solidariedade à causa nacional palestina. A desproporcionalidade do potencial bélico e do número de vítimas civis em Gaza e em Israel chocou a opinião pública, levando a uma série de críticas à política militarista de Israel, abalando sua imagem na comunidade internacional. Esse fato é importante por instigar cidadãos de diferentes nacionalidades a se informarem sobre a realidade no Oriente Médio e por conscientizá-los de que possuem o poder de exercer pressão sobre as políticas de seus governos e de se expressar sobre diferentes causas que lhes interessem fora de seu próprio território.

De modo geral, o ano de 2014 representou uma série de continuidades e mudanças em diferentes aspectos do conflito entre Israel e Palestina. . O modelo de negociações entre israelenses e palestinos parece ter falhado de modo possivelmente definitivo, fazendo com que a liderança política palestina da ANP adote medidas unilaterais e recorra à órgãos da Organização das Nações Unidas. Porém, a ineficiência da ONU e as limitações de sua atuação pelos interesses específicos das principais potências que compõem o Conselho de Segurança evidenciam a necessidade de se repensar a entidade e reformulá-la de forma que se torne mais representativa das demais nações. Por outro lado, a liderança do Hamas, que até o momento aceitou conformar um governo de união com o Fatah, ganha força dentre a população palestina e mistifica a real natureza da reivindicação palestina, que se refere ao estabelecimento de um lar nacional próprio, ao adotar um posicionamento extremista. 0 mesmo vale para Israel, que segue políticas contrárias às determinações da ONU e rompe com leis internacionais ao continuar com a expansão de assentamentos e quebra de direitos humanos dos palestinos, mostrando uma linha ideológica nacionalista cada vez mais radical. Na tendência oposta, vê-se uma campanha de solidariedade, um engajamento sociopolítico global mais afinado com as questões humanitárias e mais exigente com as decisões tomadas em âmbito internacional, abrindo novos caminhos de atuação e participação para uma resolução pacífica para o longo conflito. 


\section{Referências bibliográficas}

DUPAS, G.; VIGEVANI, T. (orgs). Israel-Palestina: a construção da paz vista de uma perspectiva global. São Paulo: Editora UNESP, 2002.

ILANI, O.; 'Wars on Gaza have become part of Israel's system of governance': An interview with filmmaker Yotam Feldman. +972 Magazine, 22 mai. 2013. Disponível em: <http://972mag.com/wars-on-gaza-have-become-part-of-israels-system-ofgovernance-an-interview-with-filmmaker-yotam-feldman/71957/ > Acessado em: 20 ago. 2014.

SHEIZAF, N. War is the new system of governance (and five other Gaza takeaways). +972 Magazine, 28 ago. 2014. Disponível em: <http://972mag.com/war-is-the-newsystem-of-governance-and-five-other-gaza-takeaways/96135/> Acessado em: 28 ago. 2014. 